\title{
Tumor-exosomes and leukocyte activation: an ambivalent crosstalk
}

\author{
Daniela Zech', Sanyukta Rana', Markus W Büchler ${ }^{2}$ and Margot Zöller ${ }^{1,3^{*}}$
}

\begin{abstract}
Background: Tumor-exosomes being reported to suppress or promote a cancer-directed immune response, we used exosomes of the rat pancreatic adenocarcinoma BSp73ASML (ASML) to evaluate, whether and which steps in immune response induction can be affected by tumor-exosomes and how the impaired responsiveness can be circumvented.

Results: ASML-exosomes bind to and are taken up by all leukocyte subpopulations in vivo and in vitro, uptake by CD11 b leukocytes exceeding that by T and B cells. ASML-exosomes affect leukocyte proliferation via reduced CD44v6 up-regulation and Ick, ZAP70 and ERK1,2 phosphorylation, which can be compensated by dendritic cells (DC). ASML-exosomes do not support $T_{\text {reg. }}$. Yet, impaired activation of anti-apoptotic signals is accompanied by slightly increased apoptosis susceptibility. IgM secretion is unaffected; NK and CTL activity are strengthened, ASML-exosomes co-operating with DC in CTL activation. ASML-exosomes transiently interfere with leukocyte migration by occupying migration-promoting receptors CD44, CD49d, CD62L and CD54 during binding/ internalization.

Conclusion: ASML-exosomes might well serve as adjuvant in immunotherapy as they support leukocyte effector functions and have only a minor impact on leukocyte activation, which can be overridden by DC. However, exosome-induced modulation of immune cells relies, at least in part, on exosome uptake and message transfer. This implies that depending on the individual tumor's exosome composition, exosomes may distinctly affect the immune system. Nonetheless, whether immunotherapy can profit from using tumor-exosomes as adjuvant can easily be settled beforehand in vitro.
\end{abstract}

Keywords: Tumor-exosomes, T cell activation, CTL, NK, Apoptosis, Leukocyte migration

\section{Background}

Exosomes, potent intercellular communicators that play a pivotal role in physiological and pathological processes [1] are found in all body fluids [2] and bind / are taken up by selected targets [3]. Exosomes contain function-competent proteins, mRNA and miRNA [1], which can severely affect the target cells $[4,5]$. These findings advocate for therapeutic use of exosomes, which is particularly appreciated in immunotherapy, as dendritic cell (DC)-exosomes, highly expressing MHCI, MHCII, CD80 and CD86, are fully equipped to initiate $\mathrm{T}$ cell activation $[6,7]$.

\footnotetext{
* Correspondence: margot.zoeller@uni-heidelberg.de 'Department of Tumor Cell Biology, University Hospital of Surgery, Im Neuenheimer Feld 365, D-69120 Heidelberg, Germany

${ }^{3}$ German Cancer Research Center, Heidelberg, Germany

Full list of author information is available at the end of the article
}

DC-exosomes being a promising means for immunotherapy $[6,8]$, hope has been dampened by tumorexosomes interfering with immune response induction [9] such that tumor growth becomes promoted [10]. Tumor-exosomes can inhibit lymphocyte, predominantly $\mathrm{CD} 4^{+} \mathrm{T}$ cell proliferation in response to IL2, which is accompanied by impaired CD25 up-regulation and stronger suppressive activity of regulatory $\mathrm{T}$ cells $\left(\mathrm{T}_{\text {reg }}\right)$, possibly due to exosome-associated TGF $\beta 1$ [11]. Impaired natural killer (NK) activity may rely on tumorexosomes inhibiting activation of Stat5, Jak3, cyclinD3 expression and perforin release [12] or on blocking NK cells via NKG2D binding as far as exosomes express the relevant receptors. Exosomal MICA*008 also provokes a NKG2D-dependent reduction in NK cytotoxicity [13]. Tumor-exosomes affect $\mathrm{T}$ cells by inducing FASmediated apoptosis [14] and by enzymatic activity, which

\section{Ciomed Central}


leads to extracellular adenosine production negatively modulating tumor infiltrating leukocytes (TIL) [15]. Tumor-exosomes may also suppress an antigen-specific response by inducing TGF $\beta 1$ and IL4 secretion and inhibiting DC maturation in draining lymph nodes [16]. Finally, tumor-exosomes can act as a decoy factor by capturing tumor-directed drugs like therapeutic antibodies as demonstrated for CD20 in hematological malignancies [17].

On the other hand, tumor-exosomes can support immune response induction. Exosomes express heat shock proteins (HSP) [18]. Stress-inducible HSP70 functions as an endogenous danger signal, promotes NK activation [19] and tumor cell lysis through granzyme B release. Exosomes recovered from heat-stressed tumor cells also were superior in inducing a tumor-antigenspecific cytotoxic $\mathrm{T}$ cell (CTL) response. Radiationinduced exosomal release of HSP72 increased IL6, TNF $\alpha$, CTL and NK activity and induced costimulatory molecule expression in DC $[20,21]$. In line with this, vaccination with staphyloccocus enterotoxin A expressing tumor-exosomes significantly inhibited tumor growth and prolonged the survival time by increasing IL2 and IFN $\gamma$ secretion and by promoting $\mathrm{T}$ helper (Th), CTL and NK activation [22]. Increased immunogenicity of exosomes from heat-stressed tumor cells is further strengthened by exosomal chemokines that attract and activate DC and T cells, whereby intratumor injection efficiently inhibited tumor growth [23]. Tumor-exosomes can be a strong immunogen such that tumor antigens, which are non-immunogenic when presented by tumor cells, induce a potent Th, CTL and B cell response and lead to a decrease in $\mathrm{T}_{\text {reg }}$, when presented by tumor-exosomes [24].

We described that exosomes of the metastasizing rat pancreatic adenocarcinoma ASML [25] support premetastatic niche preparation in draining lymph nodes [26]. Building on the proteome [26], mRNA and miRNA profile of ASML-exosomes [http://www. ncbi.nlm.nih.gov/geo, accession No GSE34739], we elaborated changes in mRNA and protein expression in a lymph node stroma line that readily takes up ASML-exosomes. Besides others, ASML-exosomes induced up-regulation of several chemokines and adhesion molecules and down-regulation of molecules controlling / inhibiting cell cycle progression (S.Rana et al., submitted) that would rather favor than inhibit cell migration and proliferation. Based on these findings we asked, whether leukocytes, too, take-up ASML-exosomes and how they respond. ASMLexosomes do not inhibit immune response induction by DC, they hamper Th activation under suboptimal stimulatory conditions, but do not interfere with effector functions.

\section{Results}

DC-derived exosomes are valuable therapeutics in cancer due to their capacity to induce $\mathrm{T}$ cell activation [6]. In contrast, tumor-exosomes may be immunosuppressive and counteract DC-exosomes [9]. To find modalities that would allow interfering with undue tumor-exosome activity, we explored tumor-exosome uptake and immune response modulation in a rat model.

\section{Leukocyte binding and uptake of tumor-exosomes}

Binding and uptake of dye-labeled ASML-exosomes by leukocytes from central and peripheral lymphoid organs was evaluated by flow-cytometry. Exosome binding increased, when titrating exosomes from $10 \mu \mathrm{g} / \mathrm{ml}$ to $40 \mu \mathrm{g} / \mathrm{ml}$ and reached a plateau below $40 \mu \mathrm{g} / \mathrm{ml}$ (data not shown). To be in the saturating dose, $40 \mu \mathrm{g} / \mathrm{ml}$ of exosomes were used throughout. Exosomes readily bound within $1 \mathrm{~h}$. However, leukocyte stripping by acid wash revealed that, with exception of peritoneal exudate cells (PEC), few leukocytes had taken-up exosomes after $1 \mathrm{~h}$ co-incubation. Exosome uptake increased until $6 \mathrm{~h}$ of co-incubation, when nearly all bound exosomes were taken-up. Highest recovery was observed in PEC, followed by spleen cells (SC), peripheral blood leukocytes (PBL), bone marrow cells (BMC) and lymph node cells (LNC). BMC behaved exceptionally, as a small population showed a very high level of exosome uptake, whereas thymocytes (TC) poorly took-up exosomes (Figure 1A, Additional file 1). ASML-exosomes were also taken-up by leukocytes in vivo. Dye-labeled exosome detection $24 \mathrm{~h}$ after i.v. injection confirmed preferential binding/uptake by PEC, followed by SC and PBL. It was low in lymph nodes and the thymus, exosomes in the thymus mostly being seen at the boundary between cortex and medulla (Figure 1B,C). Detection of dyelabeled exosomes after $48 \mathrm{~h}$ did not differ significantly from that after $24 \mathrm{~h}$ and started to decrease after $72 \mathrm{~h}$ (data not shown).

We next explored in vitro and in vivo, which subpopulations in peripheral lymphoid organs preferentially takeup ASML-exosomes. In vitro uptake was evaluated after $4 \mathrm{~h}$ co-incubation. With the exception of macrophages $(\mathrm{M} \phi)\left(\mathrm{CD} 11 \mathrm{~b}^{+}\right)$and $\mathrm{DC}\left(\mathrm{CD} 11 \mathrm{c}^{+}\right)$, which most efficiently took-up tumor-exosomes, uptake by $\mathrm{CD} 4^{+}, \mathrm{CD}^{+}$ and $\operatorname{sIgM}^{+}$lymphocytes was in a comparable range and uptake by granulocytes was lower (Figure 2A). A similar profile of exosome uptake was seen $24 \mathrm{~h}$ after in vivo application. Counterstaining of spleen and lymph node sections revealed that exosomes co-localized only with $\mathrm{CD} 11 \mathrm{~b}$ and CD11c, though exosomes were also seen in $\mathrm{CD}^{+}$and $\mathrm{CD}^{+}$cells (Figure 2B,C). This suggested that $\mathrm{CD} 11 \mathrm{~b}$ and $\mathrm{CD} 11 \mathrm{c}$, but not $\mathrm{CD} 4$ or $\mathrm{CD} 8$ are involved in exosome uptake. 

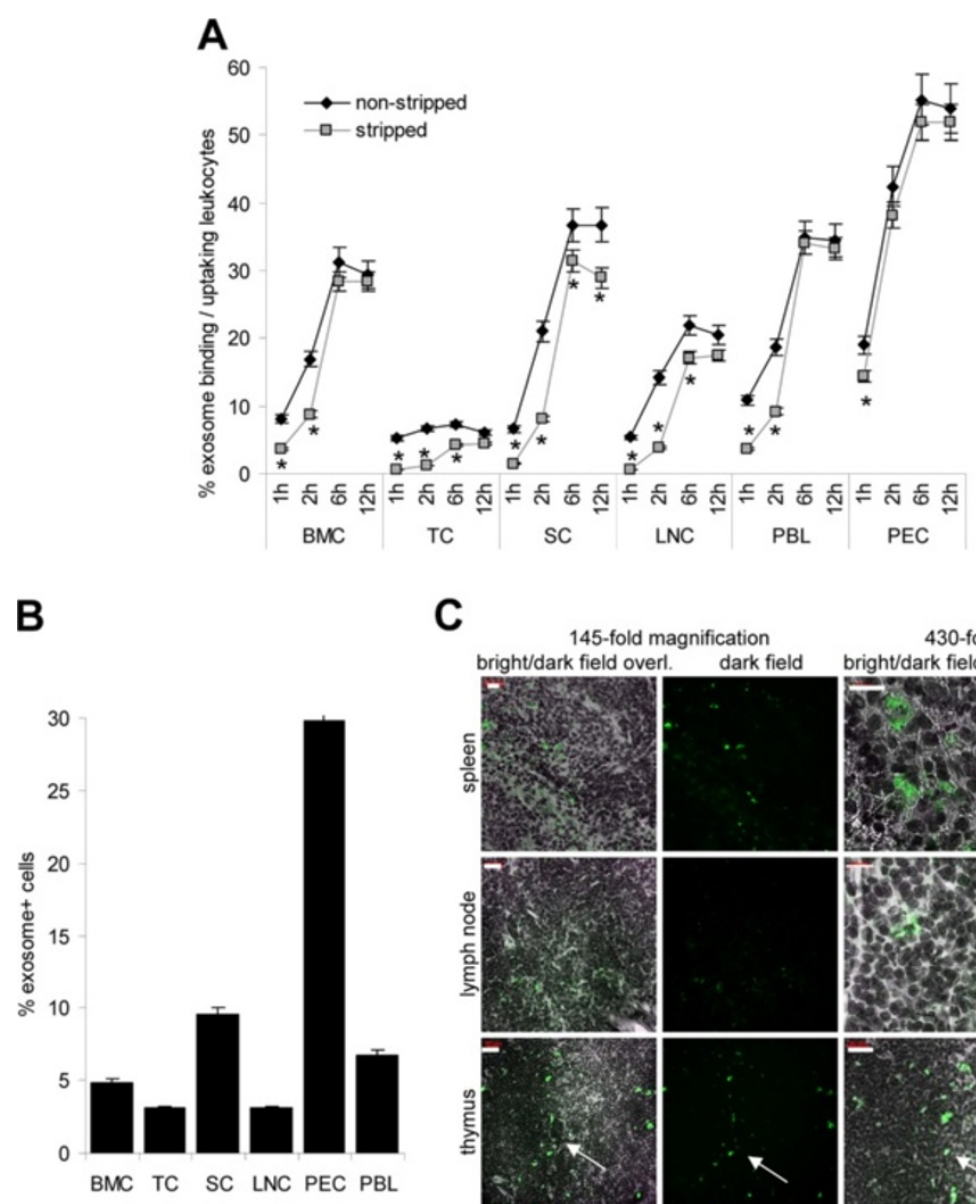

C

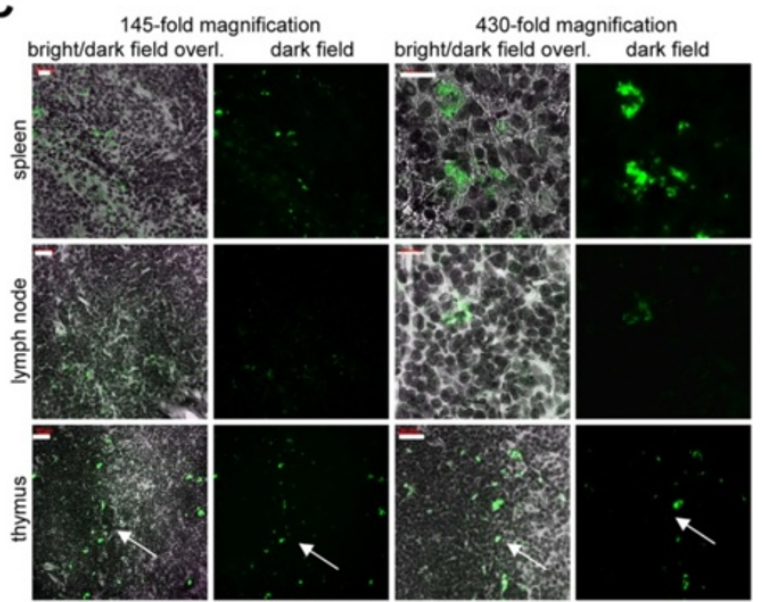

Figure 1 Tumor-exosome uptake by leukocytes. (A) BMC, TC, SC, LNC, PBL and PEC were incubated at $37^{\circ} \mathrm{C}$ with RhDHPE-labeled ASML-exosomes for the indicated periods. Exosome binding and uptake (fluorescence after 2 acid washes) was evaluated by flow-cytometry: Mean percent \pm SD (3 experiments) of exosome $e^{+}$leukocytes. Significant differences between exosome binding/uptake versus uptake:

*. (B,C) SP-Dio ${ }_{18}$ (3)-labeled exosomes $(200 \mu \mathrm{gg})$ were injected i.v. and hematopoietic organs were excised after $24 \mathrm{~h}$ : (C) Mean percent \pm SD (3 rats) of exosome ${ }^{+}$leukocytes evaluated by flow-cytometry. (D) Confocal microscopy showing representative examples of exosome ${ }^{+}$cells in shock frozen lymph node, spleen and thymus (arrow: boundary cortex/medulla) sections (scale bar left: $20 \mu \mathrm{m}$, right: $10 \mu \mathrm{m}$ ). Tumor-exosomes bind and are taken up in vitro and in vivo by cells from all hematopoietic organs. Uptake is most rapid and abundant in PEC.

Previous work showing exosomal tetraspaninintegrin complexes to bind to integrin receptors on stroma and endothelial cells $[27,28]$, we asked whether ASML-exosomes also bind to leukocyte adhesion molecules. Besides $\mathrm{CD}_{11} \mathrm{~b}^{+}$and $\mathrm{CD}_{11 \mathrm{c}^{+}}$leukocytes, exosomes were preferentially incorporated into

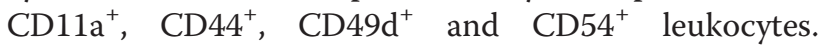
$\mathrm{CD} 2 \mathrm{~L}^{+} \mathrm{SC}$ also showed a relative increase in tumorexosome uptake (Figure 3A). To investigate whether these adhesion molecules are directly engaged, leukocytes were pre-incubated with antibody. To avoid uptake, antibody blocking studies were performed at $4^{\circ} \mathrm{C}$ (30 min). A blockade of CD11b, CD11c, CD44, CD49d, CD54 and CD62L on LNC and SC interfered with exosome binding $\left(2 \mathrm{~h}, 4^{\circ} \mathrm{C}\right)$. Binding to PEC was most strongly inhibited by anti-CD11b and anti-CD54. At the level of the exosomes, a blockade of the tetraspanins CD9 and CD81 interfered with binding (Figure 3B).

Taken together, (i) tumor-exosomes bind and are taken-up in vitro and in vivo by T cells, NK, B cells, DC, $\mathrm{M} \phi$ and granulocytes; (ii) leukocyte subpopulations differ in tumor-exosome uptake, which for ASML-exosomes is highest for PEC and lowest for granulocytes; (iii) differences in tumor-exosome uptake depend on the availability of leukocyte ligands for exosomal receptors, where CD11b, CD11c, CD44, CD49d, CD54 and CD62L are engaged in ASML-exosome binding; (iv) as previously shown [28], exosomes bind via tetraspanin complexes.

\section{Tumor-exosomes can inhibit leukocyte proliferation and} weaken apoptosis resistance

Exosome binding can initiate signal transduction via activation of target cell ligands. However, exosomes also 


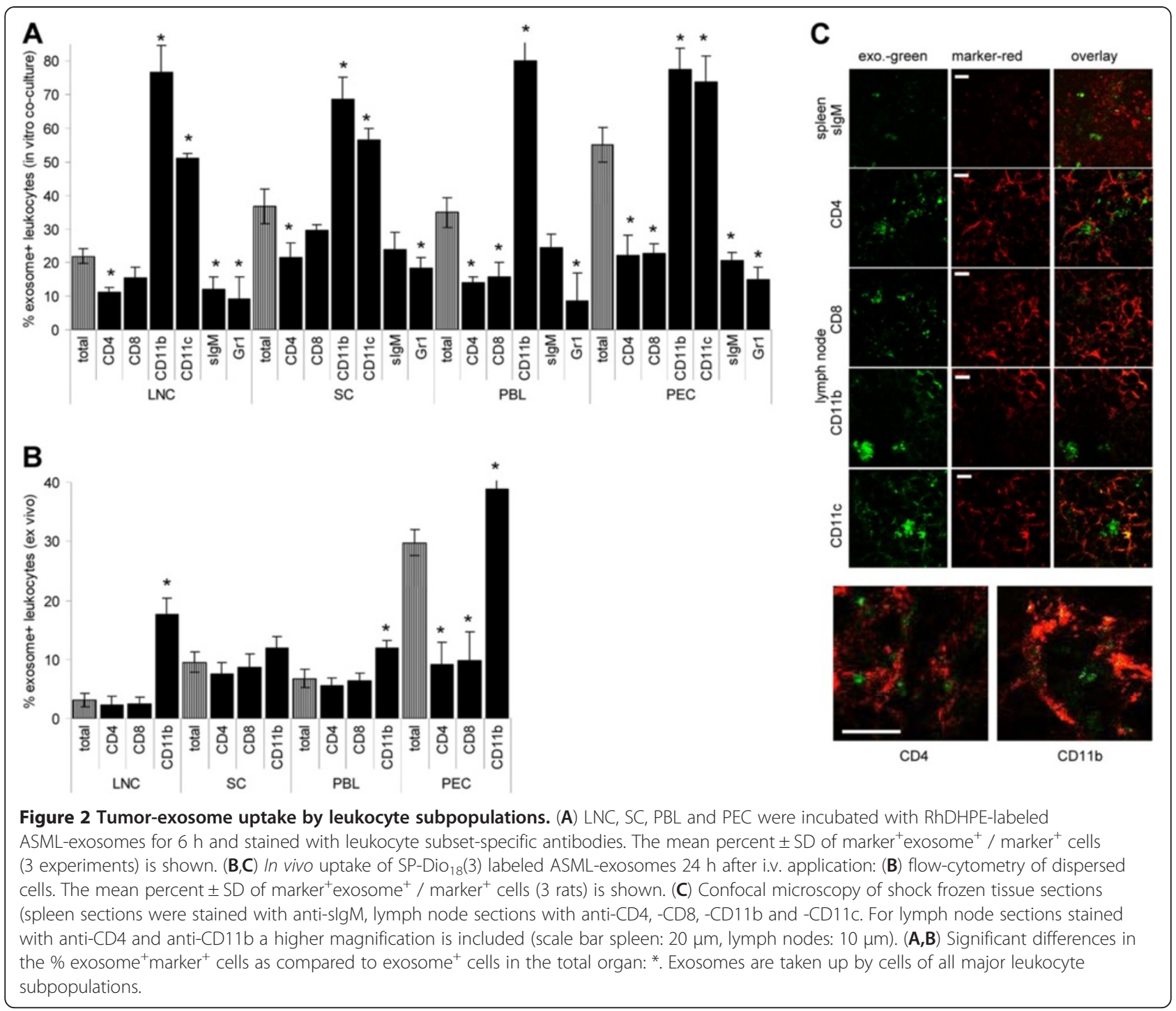

are taken-up by target cells and the uptaken exosomes exert long-lasting effects on their targets [29]. Furthermore, as exosome binding and uptake proceed concomitantly, it is difficult to define effects initiated exclusively by binding. Finally, the impact of ASML-exosomes on a lymph node stroma line was analyzed in detail showing that proteins, mRNA and miRNA are transferred, target cells being mostly affected by exosomal miRNA [26], http://www.ncbi.nlm.nih.gov/geo, accession No GSE34739, Rana et al., submitted. For these reasons we evaluated the impact of uptaken exosomes on leukocyte activity, the exosomes being present throughout the culture period, but at least for $6 \mathrm{~h}$.

Though ASML-exosomes did not promote a major redistribution of $\mathrm{T}$ cell subsets (Additional file 2), proliferative activity, evaluated by ${ }^{3} \mathrm{H}$-thymidine incorporation, was impaired. The response to IL2 and tumor-lysate (as nominal antigen) was more strongly affected than the response to the polyclonal $\mathrm{T}$ cell stimulus ConA. Low proliferative activity in the absence of a stimulus and in response to LPS was not affected. CFSE dilution confirmed these findings. Notably, when LNC were supported by antigen-loaded DC, proliferation-suppressive activity of ASML-exosomes was effaced (Figure 4A,B). Further, tumor-exosomes did not affect DC maturation. CD11c, CD80 and CD86 expression was unimpaired and MHCII, IFNY and CXCR4 expression was augmented, when DC were matured in the presence of ASMLexosomes (Figure 4C).

Reduced proliferative activity could have been due to myeloid-derived suppressor cell (MDSC) or $\mathrm{T}_{\text {reg }}$ expansion, apoptosis induction or impaired $\mathrm{T}$ cell activation by ASML-exosomes.

Independent of the presence of DC, tumor-exosomes did not promote MDSC or $\mathrm{T}_{\text {reg }}$ expansion (Figure $5 \mathrm{~A}, \mathrm{~B}$ ). However, ASML-exosome-treated lymphocytes showed 


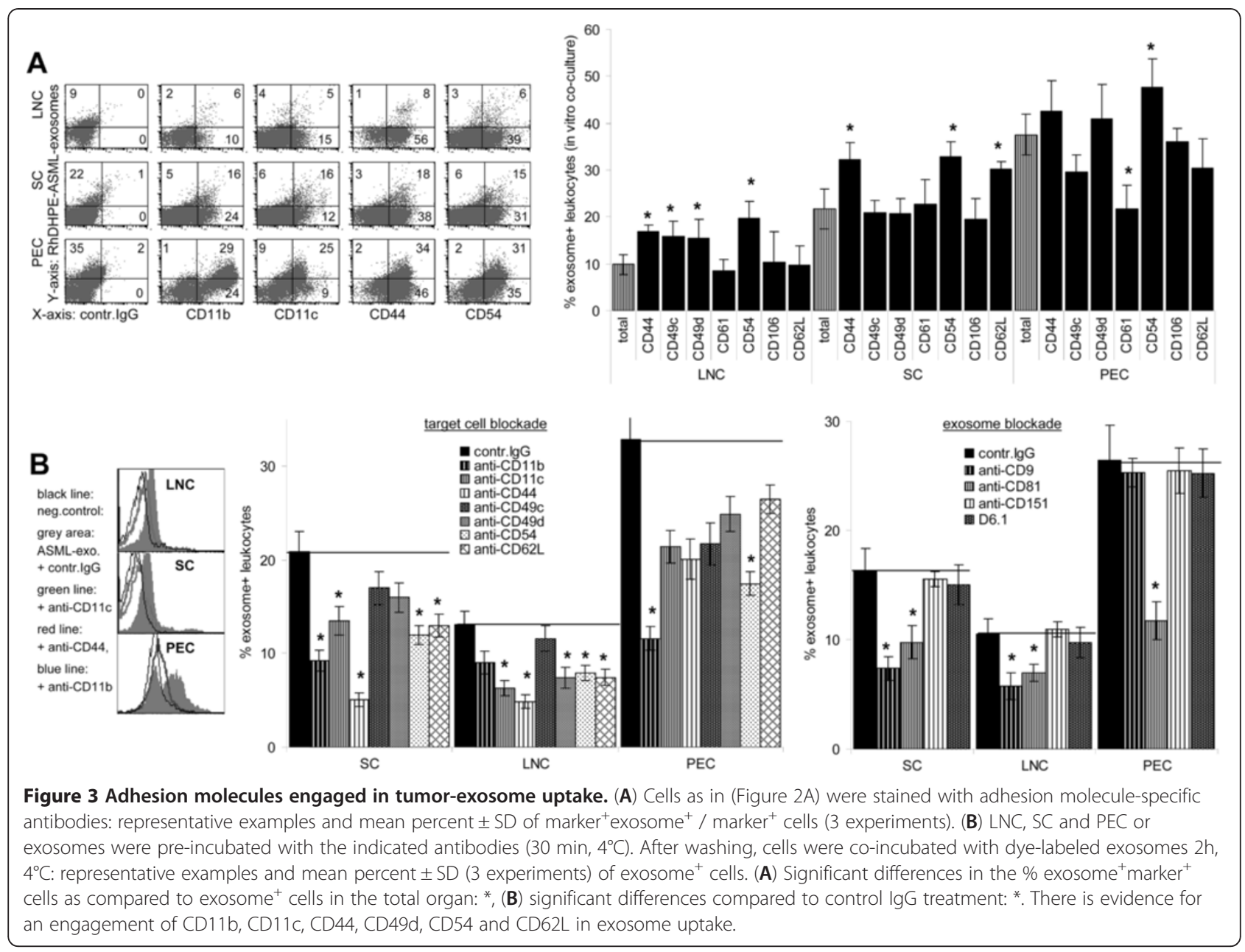

slightly increased apoptosis susceptibility (Figure 5C). Furthermore, up-regulation of the accessory molecule CD44v6 [30], though not of CD25 and CD28, was reduced in IL2 or ASML-lysate stimulated cells. CD44v6 expression was not significantly reduced in the presence of ConA or DC (Figure 5D).

Having excluded MDSC and $T_{\text {reg }}$ to account for reduced proliferative activity in the presence of ASMLexosomes, we searched for the mechanism underlying the slightly increased apoptosis susceptibility. CD95L (CD178) expression was slightly increased in LNC and SC co-cultured with ASML-exosomes that was not seen in the presence of DC. TNF $\alpha$ expression was only increased in SC, TRAF4 expression was not affected and Trail expression was reduced (Figure 6A). Despite slight CD95L up-regulation, Caspase8 expression, Caspase9 cleavage and Caspase3 activation were unaltered (Figure 6B), which excludes CD95L up-regulation to contribute to lymphocyte suicide. Searching for changes in the mitochondrial pathway of apoptosis and apoptosis protection revealed unaffected Bax, Bid, Bak, Smac/ Diablo, XIAP and cytochromeC expression in ASML- exosome-treated LNC and SC (Figure 7A). Instead, PI3K and Akt phosphorylation was slightly, but significantly reduced. BAD phosphorylation and $\mathrm{Bcl} 2$ and $\mathrm{BclXl}$ expression also was slightly affected in LNC and SC and, though mitigated, in cultures containing DC (Figure 7B, Additional file 3A). Thus, impaired anti-apoptotic signaling may account for the slightly increased lymphocyte apoptosis-susceptibility.

Reduced CD44v6 expression in LNC and SC was accompanied by a reduction in Lck, ZAP70 and Lat phosphorylation and impaired activation of the MAPK (ERK1,2) cascade. The JNK pathway (JNK, c-jun) and $\mathrm{NF}_{\kappa} \mathrm{B}$ (IKB phosphorylation) were not affected. When activation of exosome-treated lymphocytes was supported by ASML-lysate-pulsed DC, Lck and ERK1,2 phosphorylation was still reduced, but ZAP70 and LAT phosphorylation was unimpaired (Figure 8, Additional file $3 \mathrm{~B})$.

Taken together, tumor-exosomes affected lymphocyte proliferation, most pronounced in response to IL2. Reduced proliferation was not due to MDSC or $\mathrm{T}_{\text {reg }}$ expansion. Instead, reduced CD44v6 expression could 

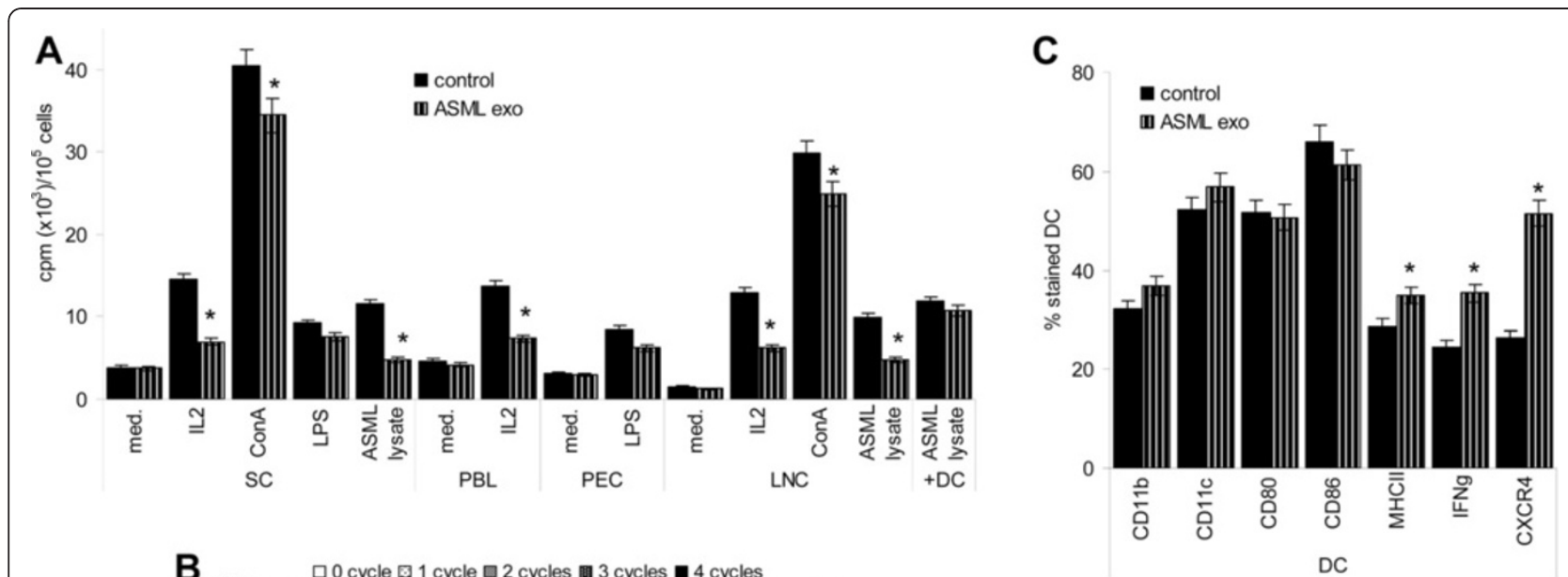

B
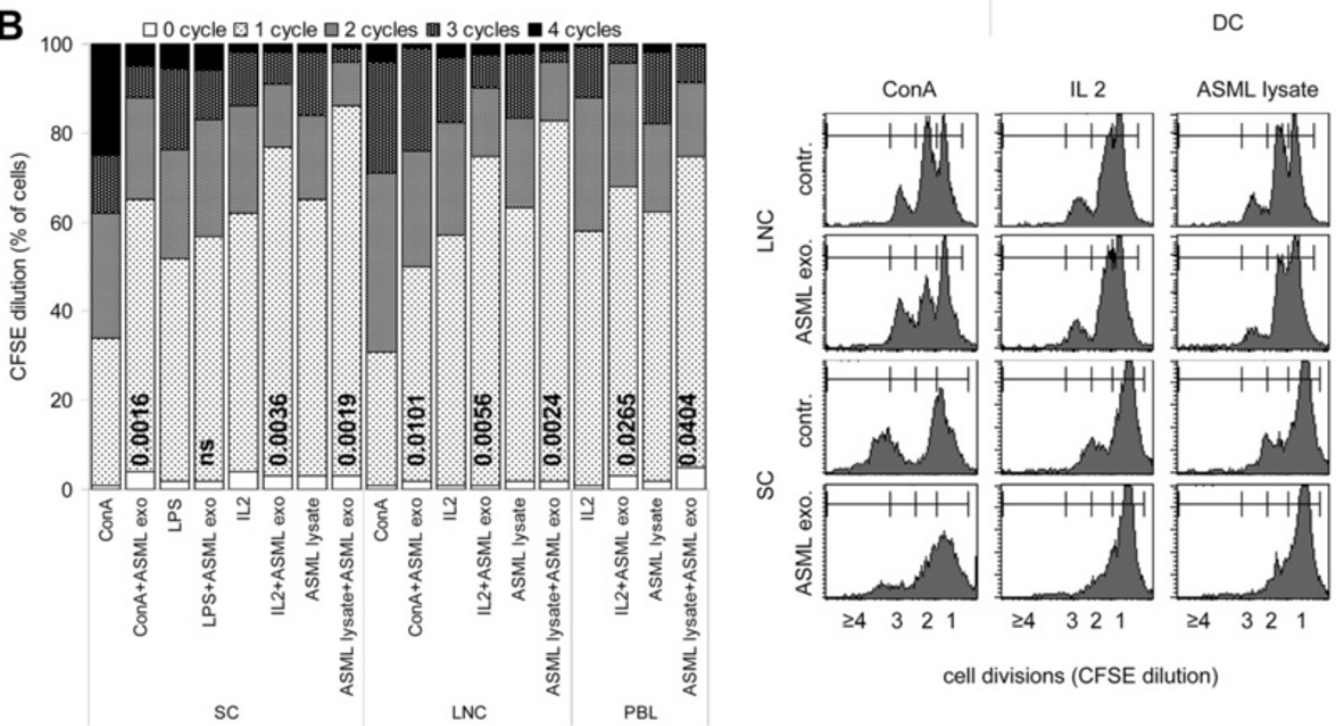

Figure 4 ASML-exosomes and leukocyte proliferation. Lymphocytes were stimulated for $72 \mathrm{~h}$ as indicated with/without ASML-exosomes Where indicated, cultures additionally contained ASML lysate-pulsed DC (LNC:DC $=10: 1)$. (A) Mean \pm SD (triplicates) of ${ }^{3}$ H-thymidine incorporation. (B) Examples of CFSE dilution in LNC and SC cultured for $72 \mathrm{~h}$ and mean percentage (triplicates) of cells that did progress through 0-4 cycles. Significant differences to cultures not containing ASML-exosomes are shown. (C) BMC-derived DC were cultured as described in MM. During the last $24 \mathrm{~h}$ of culture in the presence of LPS, ASML-exosomes were added where indicated: Mean percent \pm SD (3 experiments) of CD11 b ${ }^{+}, C^{2} 11 \mathrm{c}^{+}$, $\mathrm{CD}^{\circ} 0^{+}, \mathrm{CD} 6^{+}, \mathrm{MHCII}^{+}, \mathrm{IFNY}{ }^{+}$and $\mathrm{CXCR4^{+ }}$ cells (flow-cytometry). (A,C) Significant differences in the presence of ASML-exosomes: * Exosomes inhibit lymphocyte proliferation, which can be circumvented by activated DC.

account for impaired activation of the PI3K/Akt pathway [31,32] and, as CD44 associates with Lck [33], for mitigated $\mathrm{T}$ cell activation, which had consequences mainly on MAPK pathway activation. However, CD28 expression and DC activation not being affected, reduced CD44v6 expression was mostly compensated in the presence of DC.

\section{Tumor-exosomes support effector lymphocytes}

ASML-exosomes did not affect B cell proliferation in response to LPS (Figure 4A) and IgM secretion was not reduced in IL2, LPS and ASML-lysate stimulated SC, LNC, PEC or in DC-supported SC co-cultured with ASML-exosomes (Figure 9A). Neither sIgM nor CD81 expression was affected (Additional file 4). Nonetheless, fyn, syk and PLCY phosphorylation was slightly reduced in SC, but not in PEC co-cultured with ASMLexosomes. There was no evidence for concomitant SHP up-regulation (Figure 9B).

Tumor-exosomes promoted NK and CTL activity. NK activity, evaluated against highly NK-susceptible AS cells [34] was most strongly supported by ASML-exosomes in response to IL2. When co-cultured with NK-enriched NKR-P1B ${ }^{+}$SC, even $10 \mu \mathrm{g} / \mathrm{ml}$ ASML-exosomes sufficed for an increase in cytotoxic activity. Furthermore, granzymeB, IL2, IFNy, TNFo, CD25 and weakly CD95L expression was upregulated in IL-2 stimulated NKR-P1B + $\mathrm{SC}$, when cultured in the presence of ASML exosomes. Stat5 phosphorylation and cyclinD3 expression was also slightly increased (Figure 9C-E). ASML-exosomes also 


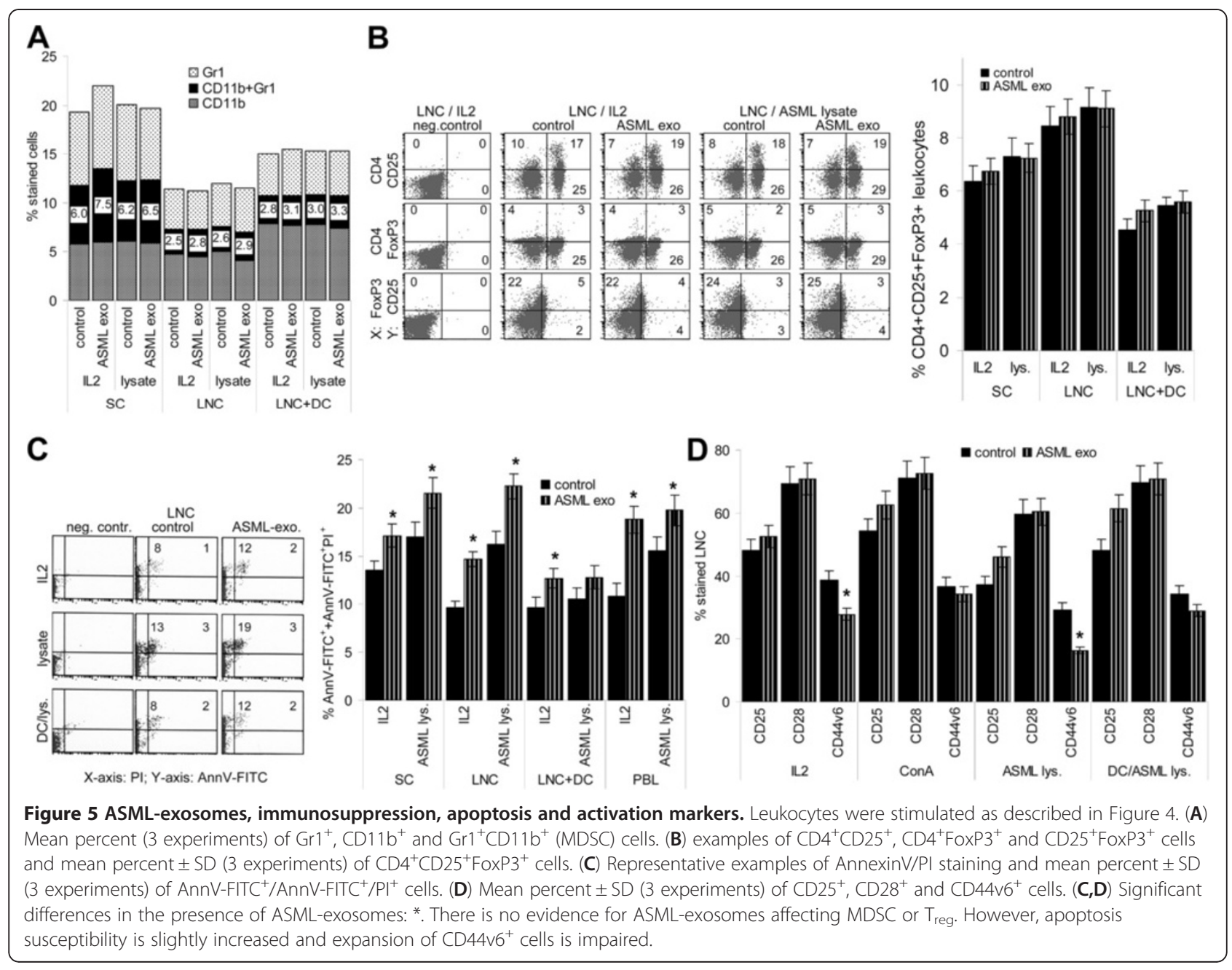

strengthened CTL activity against NK-resistant ASML cells, and exerted co-operative activity with tumorlysate-loaded DC, which by themselves stimulated CTL activation. ASML-exosomes also promoted, albeit weakly, activation of auto-reactive CTL (syngeneic blasts) (Figure 9F).

Though primary B cell responses were unimpaired, the discrete differences in activation of signaling molecules associated with $B$ cell activation suggest ASMLexosomes to possibly affect $\mathrm{B}$ cell response regulation. ASML-exosomes strongly promoted NK and CTL activity, the latter in co-operation with DC.

\section{Tumor-exosomes and $\mathrm{T}$ cell migration}

A tumor-specific immune response can only become effective, when activated lymphocytes reach the tumor [35]. Thus, an impact of ASML-exosomes on T cell migration could be a hindrance.

When evaluating magnetic bead-enriched lymph node $\mathrm{T}$ cell migration in the presence of ASML-exosomes, PMA-stimulated $\mathrm{T}$ cell migration was hardly affected, but that of IL2 and ASML-lysate stimulated T cells was mitigated (Figure 10A). As adhesion molecule expression was not or minimally (CD18 and CD62L) affected (Additional file 5), we questioned whether ASMLexosomes may transiently occupy adhesion molecules required for migration. Indeed, migration of lymphocytes that had been pretreated, but did not contain ASMLexosomes during migration was far less reduced (Figure 10A). This finding pointing towards impaired availability of adhesion molecules contributing to the ASML-exosome-mediated blockade in T cell migration, we controlled, which antibodies interfere with migration in the absence of exosomes. $\mathrm{T}$ cell migration was strongly affected by anti-CD49d, anti-CD44, anti-CD62L and anti-CD54 (Figure 10B). As CD44, CD49d, CD62L and CD54 are engaged in exosome binding (Figure 3B), we speculated that exosomes should not be inhibitory for $\mathrm{T}$ cells pre-incubated with these antibodies. In fact, ASML-exosomes did not further reduce migration of antibody-pre-incubated T cells (Figure 10C). From there we conclude that the inhibitory effect of ASML- 


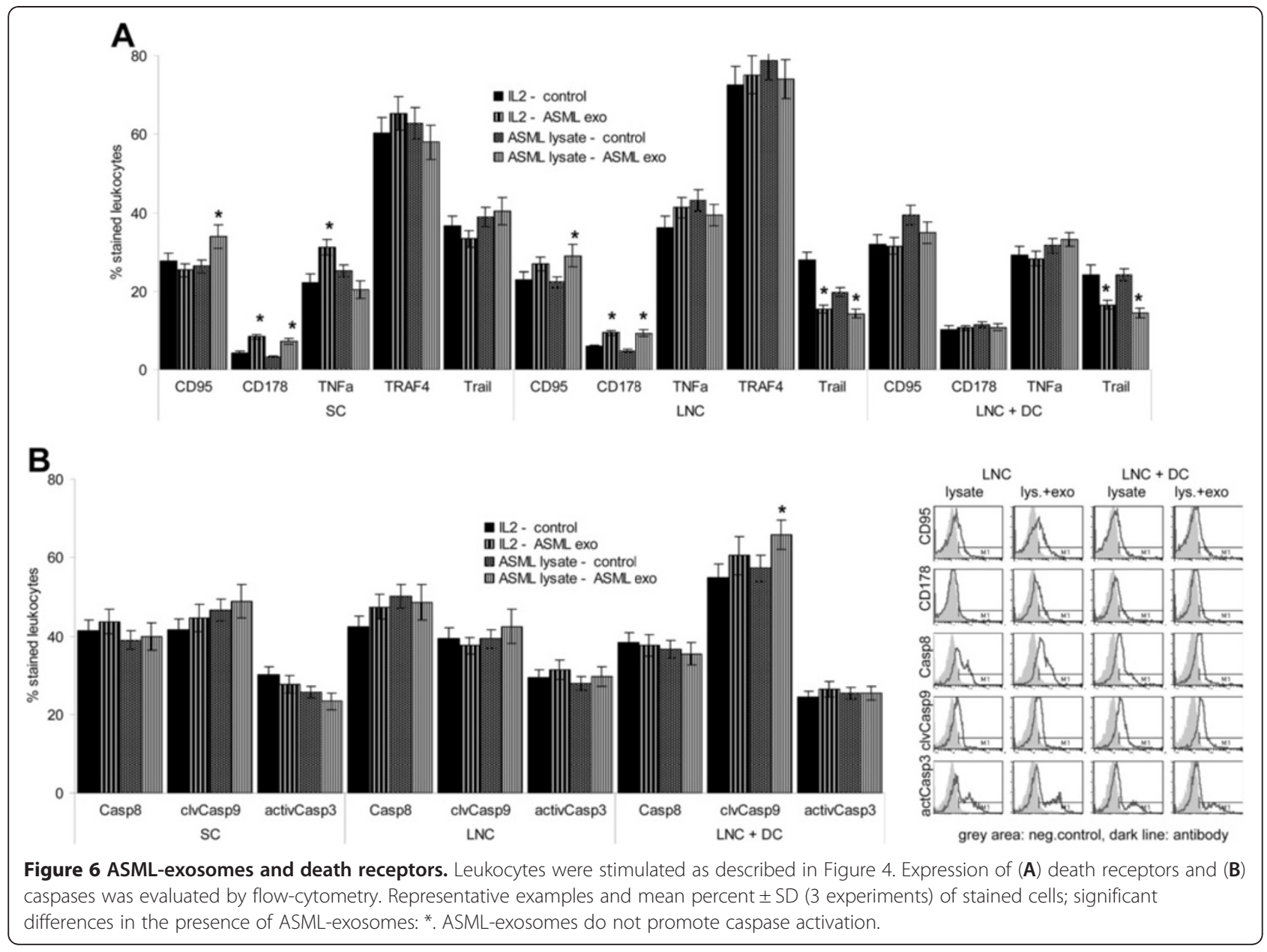

exosomes is mostly due to transient occupancy of adhesion molecules required for migration. In line with this, SDF1 and CXCR4 expression was not reduced, FAK and ezrin phosphorylation was not and src phosphorylation was only slightly impaired in ASML-exosome treated T cells (Figure 10D).

Thus, exosome binding and/or the internalization of the exosome ligand(s) during uptake mostly accounts for transiently impaired $\mathrm{T}$ cell migration.

\section{Tumor-exosomes and leukocyte activation in vivo}

To control for the impact of tumor-exosomes on leukocyte activation in vivo, BDX rats received subcutaneous injections of $2 \times 10^{6}$ ASML lysate-loaded DC and 2-times/week $500 \mu \mathrm{g}$ ASML-exosomes (i.v.). Rats were bled and sacrificed $3 \mathrm{~d}$ after the $3^{\text {rd }}$ DC injection, the draining axillary and inguinal lymph nodes and the spleen were excised and analyzed.

DC vaccination was accompanied by an $>2$-fold increase in the number of draining LNC, which was further increased, when rats received concomitantly ASML-exosomes (Figure 11A). DC vaccination promoted a slight expansion of $\mathrm{CD} 4^{+}, \mathrm{CD}^{+}$and $\mathrm{CD} 11 \mathrm{c}^{+}$ cells. Exosomes induced expansion of $\mathrm{CD} 1 \mathrm{~b}^{+}$cells. DC vaccination also induced CD25, CD28, CD44v6, CD80, CD86, IL2, IL12 and IFN $\gamma$ upregulation. Only CD25 and CD80 upregulation was not seen in rats concomitantly receiving ASML-exosomes. (Figure 11B, Additional file 6A). Exosome application did not affect $\mathrm{T}_{\text {reg }}$ and an expansion of MDSC was only seen in the peripheral blood, though not in rats concomitantly receiving DC (Figure 11C, Additional file 6B). Unexpectedly, ASMLexosomes did not inhibit, but rather promoted LNC, $\mathrm{SC}$ and, most pronounced, $\mathrm{PBL}$ proliferation in vivo. High proliferative activity of lymphocytes from rats receiving DC was not affected by concomitant ASMLexosome application. This was independent of whether lymphocytes were restimulated in vitro by IL2, ASML lysate or ASML lysate plus exosomes (Figure 11D). The cytotoxic activity of LNC and SC also was unimpaired in rats receiving lysate-pulsed DC plus ASMLexosomes and lymphocytes from rats treated with ASML-exosomes showed increased CTL activity compared to untreated controls. NK activity was hardly 


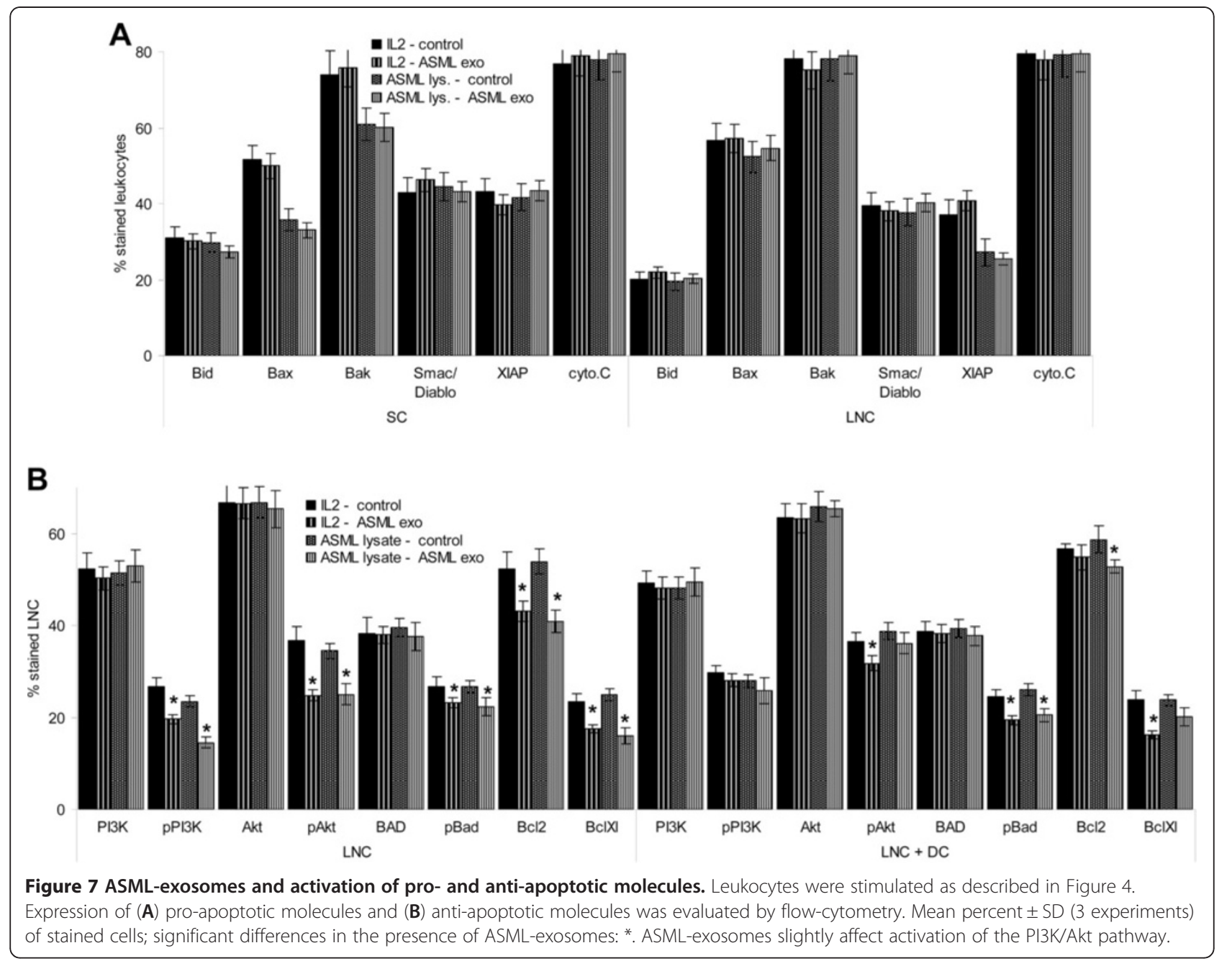

affected by DC, exosome or DC plus exosome treatment (Figure 11E).

With the exception of an increase in MDSC in the peripheral blood of ASML-exosome-treated rats, these ex vivo data confirm the results obtained after in vitro co-culture and show that in vivo ASMLexosomes support immune response induction by tumor-lysate-loaded DC.

\section{Discussion}

Tumor-exosomes are discussed to possibly provide a hindrance in immunotherapy by suppressing immune response induction as well as immune effector cells [9]. However, opposing findings have also been observed $[23,36]$. We approached the question using exosomes of a highly metastatic rat pancreatic adenocarcinoma, where pancreatic adenocarcinoma are known for their intense interaction with the surrounding tissue including TIL [37]. Though ASML-exosomes interfere with leukocyte activation in vitro, they did not affect or supported effector cells and a reduction in T cell migration was transient. These findings - not excluding immunosuppression by other tumor-derived vesicles - argue against tumor-exosomes being a hindrance in immunotherapy.

\section{Tumor exosome binding and uptake}

Tumor-exosomes bind and are taken-up by leukocytes in central and peripheral lymphoid organs, though binding/uptake varies considerably being highest for PEC and lowest for TC. As a very similar profile of binding/ uptake was observed in vitro and in vivo, the low uptake by $\mathrm{TC}$ cannot exclusively rely on poor accessibility of the thymus. Also, the high recovery of exosomes in PEC cannot be explained by "first station" capture that would be the spleen after i.v. injection. Thus, exosome uptake is a directed process that is particularly efficient in $M \phi$ and DC.

Exosome uptake by solid organ-derived cells mostly proceeds via binding of tetraspanin-associated adhesion molecules to their target cell ligands [27,28]. Antibody-blocking studies revealed CD11 integrins, 


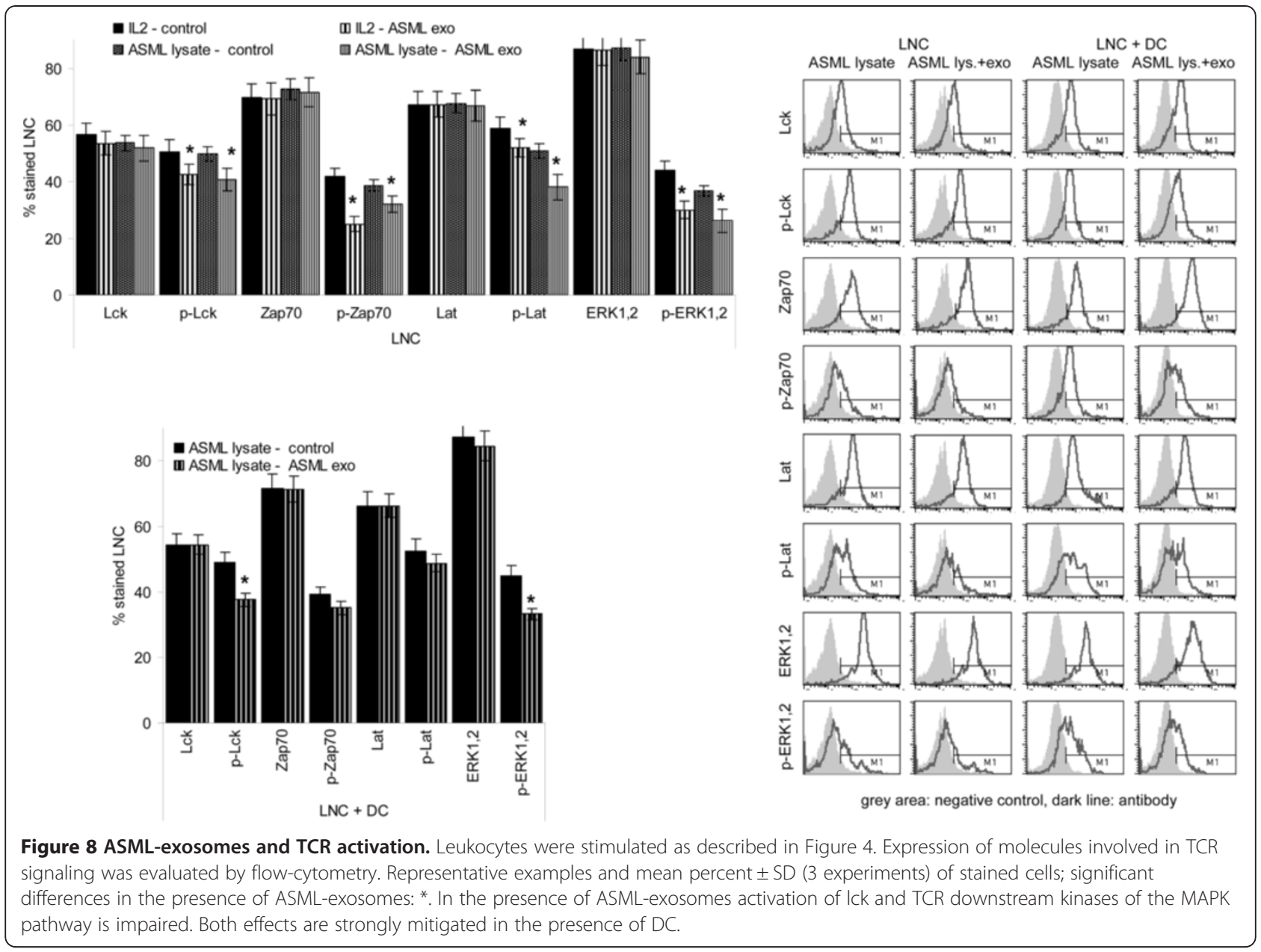

CD49d, CD44, CD54 and CD62L to be engaged in exosome uptake, where up-regulated CD44 and CD49d expression on activated lymphocytes [38] and CD11c on activated DC [39] could facilitate exosome binding. Similar to AS-exosomes (28), ASMLexosomes mostly use (CD9 and CD81) tetraspanin complexes for leukocyte binding. Uptake by $\mathrm{M} \phi$ may proceed distinctly from that by lymphocytes. Binding of Annexins to scavenger receptors can play a role in exosome uptake $[40,41]$. The more rapid exosome uptake by $M \phi$ that is mostly inhibited by anti-CD $11 b$ argues for Annexin possibly being important in exosome uptake by $\mathrm{\phi} \phi$.

Taken together, tumor-exosomes uptake by $\mathrm{CD}_{11 \mathrm{~b}^{+}}$ M $\phi$ may preferentially proceed via scavenger receptors, uptake by lymphocytes and dendritic cells via adhesion molecule ligands for exosomal receptors in tetraspanin complexes. Exosome uptake by leukocytes will vary according to the leukocyte ligands as well as exosomal (tetraspanin)-adhesion molecule complexes.
Tumor-exosomes and lymphocyte activation

Proliferation of $\mathrm{T}$ cells stimulated in the presence of tumor-exosomes was reduced, most pronounced when stimulated by IL2.

Tumor-exosomes can strengthen MDSC [42,43] and $\mathrm{T}_{\text {reg }}$ expansion/activation $[11,44,45]$, but also impair $\mathrm{T}_{\text {reg }}$ expansion [24]. We did not observe any effect on $\mathrm{T}_{\text {reg }}$ and only in vivo an increase in MDSC in the peripheral blood. These findings exclude ASML-exosomes to impair lymphocyte activation due to active suppression.

Tumor-exosomes can induce lymphocyte apoptosis via CD95L and TRAIL $[46,47]$. Although there was a slight increase in $\mathrm{CD}_{95} \mathrm{~L}^{+}$lymphocytes and in early (AnnV $\left.{ }^{+} / \mathrm{PI}^{-}\right)$apoptotic lymphocytes, co-culture with ASMLexosomes did not suffice to initiate receptor-mediated apoptosis or to activate the mitochondrial apoptosis pathway. Instead, ASML-exosomes slightly affected activation of anti-apoptotic molecules of the PI3K/Akt pathway. This could well be a consequence of impaired CD44v6 upregulation, CD44v6 supporting liberation of 


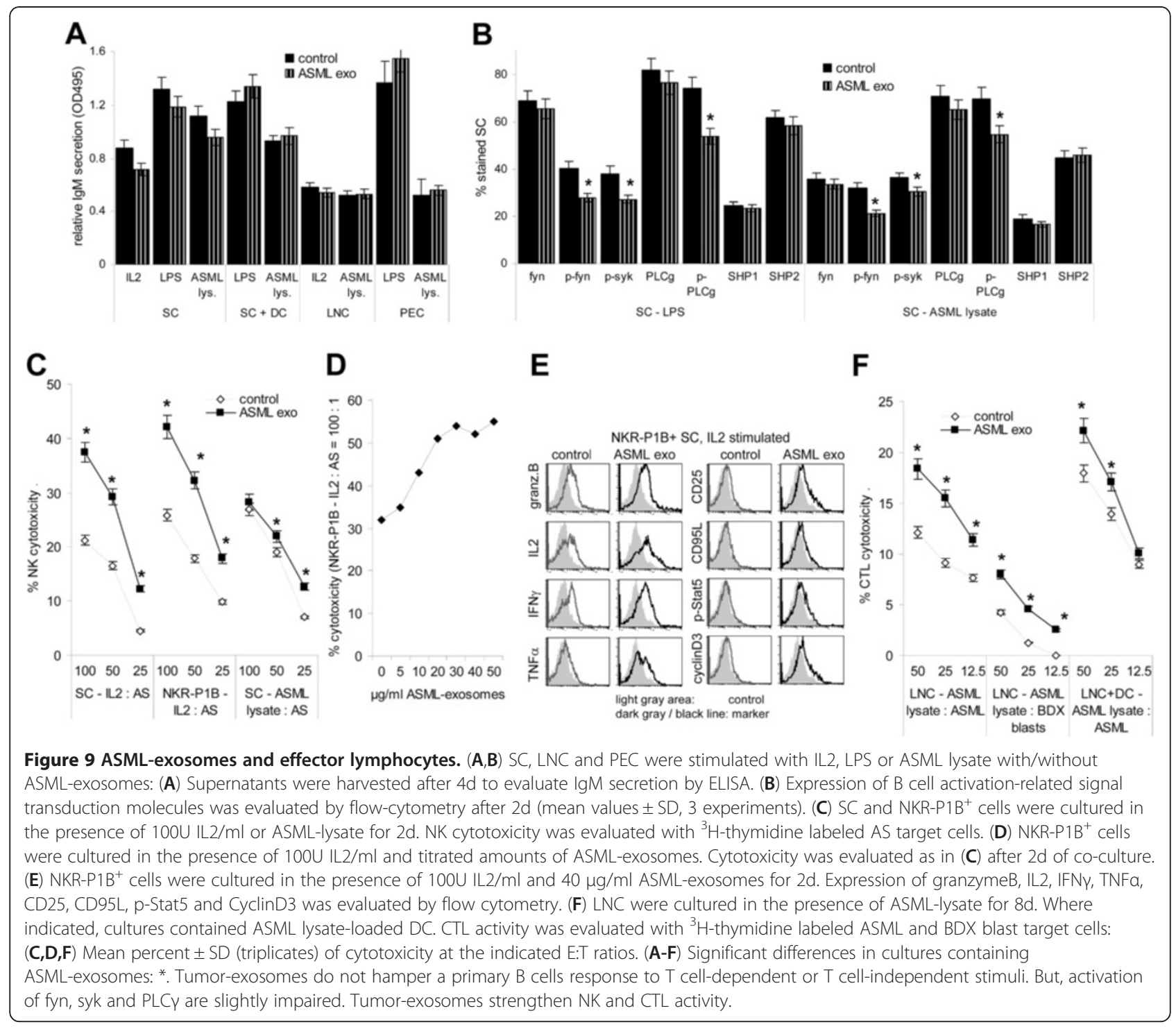

Bcl2 and Bcl-Xl from BAD via activation of the MAPK pathway $(31,32)$.

Proliferation being most strongly suppressed in response to IL2, but not in the presence of DC, also points towards an impact of ASML-exosomes on accessory molecule, particularly CD44 activation. During lymphocyte activation CD44 associates with lck, which becomes phosphorylated and contributes to ZAP70 phosphorylation [48]. CD44v6 also can directly promote MAPK pathway activation $[26,49]$. In cultures containing ASML-exosomes, lck, ZAP70, LAT and ERK1,2 phosphorylation was significantly, though not strongly reduced, possibly due to support by other accessory molecules like CD25, CD28 or CD40L. Notably, in cocultures with DC, lck and ERK1,2 phosphorylation, but not ZAP70 and LAT phosphorylation remained reduced. Thus, in the presence of antigen-loaded DC showing high CD40 expression, impaired CD44v6-initiated signaling becomes invalidated.

Taken together, tumor-exosomes inhibit Th expansion/activation in response to IL2. The inhibitory effect can be circumvented by provision of appropriate second signals, e.g. via DC. There was no evidence for exosomes affecting signals directly initiated by TCR engagement. In line with this, no changes in signal transduction molecule activation were seen after $1 \mathrm{~h} \mathrm{co-}$ incubation of leukocytes with exosomes (data not shown). Moreover, ASML-exosomes hardly promote apoptosis and not immunosuppression, which findings were confirmed in vivo.

\section{Tumor-exosomes and lymphocyte effector functions}

ASML-exosomes did not interfere with a primary $\mathrm{B}$ cell response. Nonetheless, fyn, syk and PLC $\gamma$ 


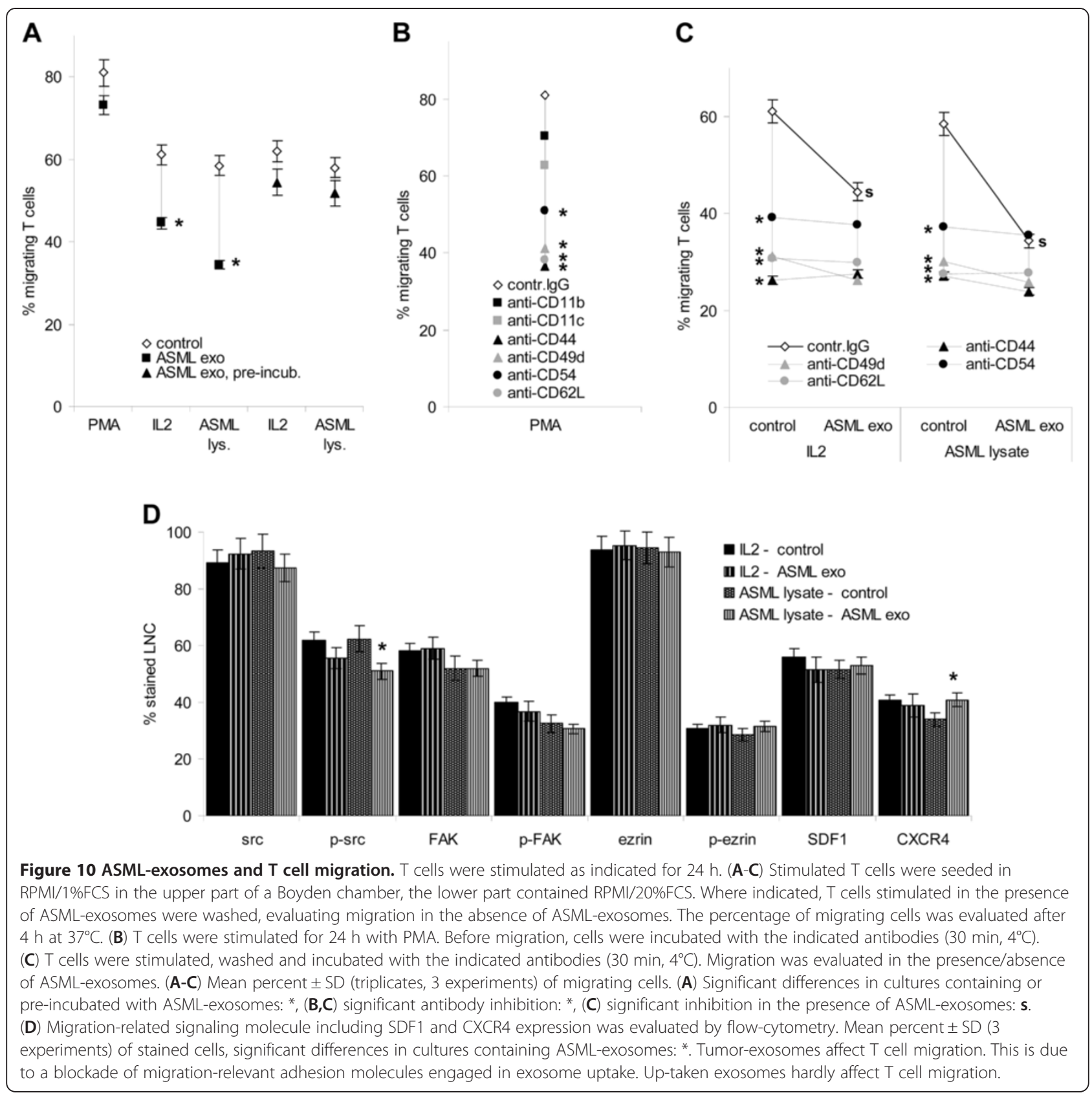

phosphorylation was slightly reduced. Although ASMLexosomes did not induce activation of phosphatases, which can dephosphorylate syk and thereby account for $\mathrm{PLC} \gamma$ down-regulation [50], we cannot exclude that ASML-exosomes may have some bearing on $\mathrm{B}$ cell response regulation.

ASML-exosomes strongly stimulated NK activity in the presence of IL2. Tumor-exosomes can suppress NK activity by inhibition of JAK/STAT pathway signal transduction, reduced perforin release or a blockade of NK activating receptors [12,13], but also can stimulate NK cells by high HSP expression [19,21], as known for ASML-exosomes [26]. Irrespective of the constitutively high NK activity of BDX rats [51], pronounced induction of GranzymeB and IFNy expression in NKR-P1B cells in the presence of ASML-exosomes argues for exosomessupported NK activation rather than suppression. The same accounts for CTL, where ASML-exosomes efficiently stimulated tumor-specific and only to a minor degree, autoreactive CTL. Importantly, ASML-exosomes 


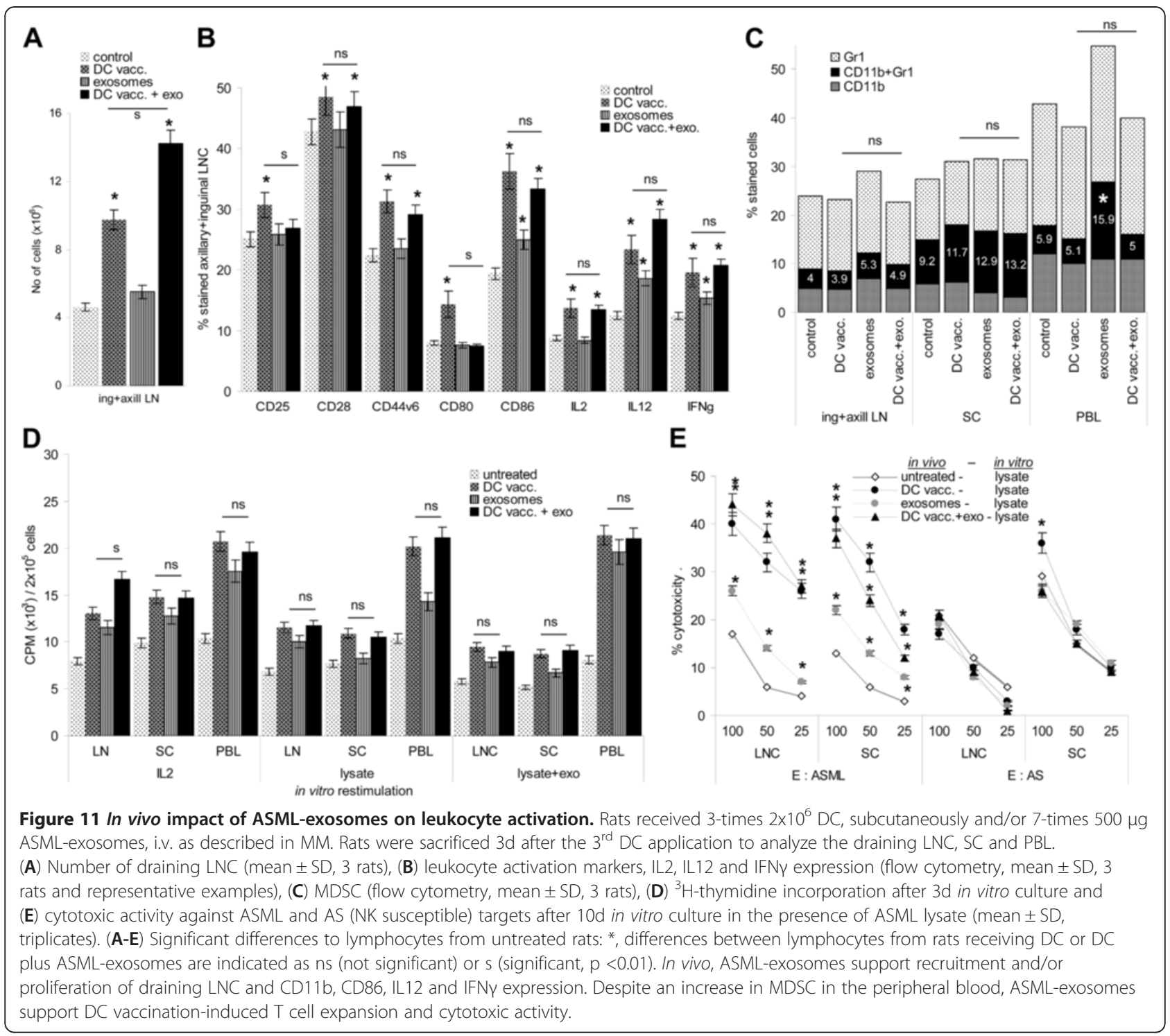

strengthened DC-supported CTL activation, probably due to tumor-exosome uptake by DC [36].

It should be mentioned that according to our protocol of prolonged leukocyte - exosome co-incubation, we missed binding-initiated activation of signaling cascades and changes in signaling pathway activation could likely be due to transferred exosomal proteins, mRNA or miRNA [5,7], where exosomal miRNA might be dominating (Rana et al., submitted). However, irrespective of whether exosomes binding or uptake slightly mitigated activation of several signal transduction pathways, ASML-exosomes did not hamper or stimulated lymphocyte effector functions in vitro and lymphocyte activation was not impaired in vivo. Thus, increased NK and CTL activity argues for ASML-exosomes as an immunotherapy supporting regimen.

\section{Tumor-exosomes and leukocyte migration}

As activated leukocytes need to reach the tumor, the impact of ASML-exosomes on T cell migration became important. Migration was significantly impaired only when leukocytes were exposed to exosome during migration and antibody blocking studies confirmed that exosomes only transiently interfered with lymphocyte migration by occupying or co-internalizing with their migrationrelevant ligands, CD44, CD49d, CD62L and CD54 [38,52]. Instead, uptaken exosomes did not affect leukocyte migration. These findings are in line with ASML-exosomes not affecting src, FAK and ezrin phosphorylation and SDF1 and CXCR4 expression. Upregulated CXCR4 expression in draining LNC after i.v. application of ASML-exosomes and leukocyte recruitment into the draining node after subcutaneous ASML- 
exosome application [26] also argue against exosomes hampering leukocyte migration in vivo.

\section{Conclusion}

ASML-exosomes were taken up by leukocytes and interfered, though not severely, with $\mathrm{T}$ cell expansion in vitro, which could be circumvented by supportive regimens like DC. They did not promote $\mathrm{T}_{\text {reg }}$ expansion and only in vivo a slight increase in MDSC was seen. T cell migration was only transiently impaired during exosome uptake. Importantly, ASML-exosomes supported effector cells and cooperated with DC [23], whereby tumorexosomes can become a stronger immunogen than a membrane-bound or soluble tumor antigen $[24,36]$. In addition, tumor-exosomes can provide a reliable source of tumor antigens in tumors where immunogenic entities are unknown. Nonetheless, as exosome-mediated intercellular communication may be dominated by transferred miRNA [5], exosomes of different tumors could distinctly affect the immune system, which can be easily evaluated in vitro before vaccinating with tumorexosomes.

\section{Methods}

\section{Cell lines}

The rat pancreatic adenocarcinoma lines ASML and BSp73AS (AS) [25] were maintained in RPMI1640/10\% FCS. Confluent cultures were detached with trypsine or EDTA and split. ASML cells are NK resistant, AS cells are highly NK susceptible [34].

Antibodies are listed in Additional file 7.

Exosomes were separated by ultracentrifugation and sucrose density gradient [28]. In brief, cells were cultured $(48 \mathrm{~h})$ in serum-free medium. Cleared supernatants $(2 \times 10 \mathrm{~min}, 500 \mathrm{~g}, 1 \times 20 \mathrm{~min}, 2000 \mathrm{~g}, 1 \times 30 \mathrm{~min}$, $10000 \mathrm{~g})$ were centrifuged $(90 \mathrm{~min}, 100000 \mathrm{~g})$ and washed (PBS, $90 \mathrm{~min}, 100000 \mathrm{~g}$ ). Crude exosome preparations were suspended in $2.5 \mathrm{M}$ sucrose, overlaid by a continuous sucrose gradient $(0.25 \mathrm{M}-2 \mathrm{M})$ and centrifuged $(15 \mathrm{~h}, 150000 \mathrm{~g})$. To exclude an impact of sucrose gradient centrifugation on exosome activity, sucrose gradient-purified exosomes were compared with the $100000 \mathrm{~g}$ pellet that was filtered through $0.20 \mu \mathrm{m}$ membranes to remove, at least, larger non-exosome vesicles. Comparative analyses of sucrose-gradient enriched and $1000000 \mathrm{~g} / 0.2 \mu \mathrm{m}$ filtered exosomes are shown in Additional file 8. As we did not observe impaired activity of sucrose-gradient enriched exosomes, all other experiments were performed with the latter exosome population. Where indicated, exosomes were prepared after rhodamine-DHPE or SP-Dio ${ }_{18}$ (3) (Invitrogen, Karlsruhe, Germany) labeling (60 $\left.\mathrm{min}, 4^{\circ} \mathrm{C}\right)$. Relative fluorescence intensity was evaluated at $540 \mathrm{~nm}$ excitation, $590 \mathrm{~nm}$ emission or $497 \mathrm{~nm}$ excitation, $513 \mathrm{~nm}$ emission, respectively, and adjusted to rhodamine-DHPE or SP$\mathrm{Dio}_{18}(3)$ standards. ASML-exosomes have been characterized for protein composition [26], mRNA and miRNA content [http://www.ncbi.nlm.nih.gov/geo/query/acc.cgi? acc $=$ GSE34739].

\section{Cell and rat tissue preparation}

Heparinized peripheral blood was collected by heart puncture. PBL were collected after Ficoll-Hypaque gradient centrifugation. PEC were collected flushing the peritoneal cavity with $10 \mathrm{ml} \mathrm{PBS/heparin.} \mathrm{BMC} \mathrm{were}$ collected from femora and tibiae, flushing the bones with $5 \mathrm{ml}$ PBS. SC and LNC were obtained by pressing the organs through fine gauze. Where indicated, cells were CFSE (Invitrogen, Karlsruhe, Germany) labeled. Subpopulations were enriched by magnetic-bead sorting (Miltenyi, Mönchen-Gladbach, Germany). DC were generated in vitro from BMC. BMC $\left(2 \times 10^{6}\right)$ were cultured in $10 \mathrm{~cm}$ diameter Petri dishes in $10 \mathrm{ml}$ RPMI1640, supplemented with $10 \mathrm{ng} / \mathrm{ml} \mathrm{rrGM}-\mathrm{CSF}$ and $2 \mathrm{ng} / \mathrm{ml} \mathrm{rrIL}-4$. On day 3 of culture, additional $10 \mathrm{ml}$ medium was added, exchanging half of the medium on day 6. Loosely adherent cells, harvested after $8 \mathrm{~d}$, were seeded in new Petri dishes in $10 \mathrm{ml}$ medium containing $1 \mu \mathrm{g} / \mathrm{ml} \mathrm{LPS}$ for $24 \mathrm{~h}$ to induce DC maturation. Matured DC were harvested on day 9, washed and loaded in serum-free RPMI with ASML-lysate (lysate of 3 cells/1 DC, overnight, $37^{\circ} \mathrm{C}$ ).

\section{Exosome binding and uptake}

Exosome binding/uptake in vitro was evaluated after $1 \mathrm{~h}-12 \mathrm{~h}$ co-incubation of dye-labeled exosomes with leukocytes. To differentiate between binding and uptake, bound exosomes were removed by two acid washes $(\mathrm{PBS} / \mathrm{HCl}, \mathrm{pH}$ 2.5) (stripping) evaluating exosome uptake by flow cytometry after fixation and permeabilization. When evaluating exosome binding structures on leukocytes or exosome targeting structures, leukocytes were incubated with the indicated antibodies for $30 \mathrm{~min}$ at $4^{\circ} \mathrm{C}$ and washed $2 \times$ with an excess of PBS. Dye-labeled exosomes, incubated with antibodies for $30 \mathrm{~min}$ at $4^{\circ} \mathrm{C}$, were resuspended in $50 \mathrm{ml}$ of PBS and centrifuged for $90 \mathrm{~min}$ at $100000 \mathrm{~g}$. Antibody-coated washed cells / exosomes were co-incubated for $2 \mathrm{~h}$ at $4^{\circ}$ $\mathrm{C}$, washed 2-times with an excess of PBS and immediately analyzed by flow cytometry. The short incubation time at $4^{\circ} \mathrm{C}$, though resulting in a lower binding rate, is mandatory to avoid exosome uptake.

Flow cytometry followed routine procedures. Where indicated, cells were fixed and permeabilized. Apoptosis was determined by AnnV/PI staining. Cell cycling was determined by CFSE dilution in labeled leukocytes. Samples were analyzed by a FACSCalibur and the Cell Quest Program. 


\section{Immunofluorescence}

Sections $(7 \mu \mathrm{m})$ of shock frozen tissues from rats that had received an i.v. injection of $200 \mu \mathrm{g}$ dye-labeled exosomes were counterstained with HE or markerspecific antibodies according to routine procedures. Digitized images were generated using a Carl Zeiss LSM780 confocal microscope and software Carl Zeiss Axioview Rel. 4.6.

\section{Proliferation assay}

LNC and SC were titrated $\left(2 \times 10^{5}-2.5 \times 10^{4}\right.$ cells/well $)$ in 96 well plates with/without $10^{4}$ ASML lysate-loaded DC and/or $40 \mu \mathrm{g} / \mathrm{ml}$ exosomes. Cells were cultured for $3 \mathrm{~d}$ adding $10 \mu \mathrm{Ci} / \mathrm{ml}{ }^{3} \mathrm{H}$-thymidine during the last $16 \mathrm{~h} .{ }^{3} \mathrm{H}$-thymidine incorporation was evaluated in a $\beta$-counter.

\section{Cytotoxicity assays}

CTL activity was evaluated after stimulating LNC with ASML lysate for $7 \mathrm{~d}$ in RPMI/10\%FCS/10U IL2/ml. ASML cells and, as control, syngeneic lymphoblasts (ConA-stimulated LNC) were used as targets. NK activity was evaluated after $2 \mathrm{~d}$ of culture of SC or NKR-P1B ${ }^{+}$ cells [53] (magnetic bead separation) in the presence of 100U IL2/ml using AS cells as target. Cytotoxicity was evaluated using the JAM assay [54]. In brief, ${ }^{3} \mathrm{H}$-thymidine-labeled target cells $\left(1 \times 10^{4} /\right.$ well $)$ were seeded on titrated numbers $\left(1 \times 10^{6}-2.5 \times 10^{5}\right)$ of effector cells in 96 well plates. After $6 \mathrm{~h}$ at $37^{\circ} \mathrm{C}$, plates were harvested, and radioactivity was determined in a $\beta$-counter. Cytotoxicity is presented as \% cytotoxicity $=100 \times$ (counts in control well - counts in test well) / (total counts/well).

\section{ELISA}

IgM secretion as evaluated according to standard ELISA protocols. Plates were coated with $10 \mu \mathrm{g} / \mathrm{ml}$ anti-rIgM (overnight, $4^{\circ} \mathrm{C}$ ). After washing and blocking, supernatants of cultures as described above were seeded on the plates overnight. Plates were washed (PBS/0,01\% Tween20) and biotinylated anti-rIgM $(2 \mu \mathrm{g} / \mathrm{ml}$ in PBS/ $0.5 \% \mathrm{BSA})$ was added. After incubation $\left(2 \mathrm{~h}, 37^{\circ} \mathrm{C}\right)$, washing $(6 \mathrm{x}, \mathrm{PBS} / 0.01 \%$ Tween 20$)$ and streptavidin-alkaline phosphatase enzyme-conjugate incubation (45 $\mathrm{min}$, room temperature), BCIP/NBT substrate was added. OD (triplicates) was measured at $495 \mathrm{~nm}$.

\section{Migration assay}

Cells were seeded in the upper part of a Boyden chamber in $50 \mu \mathrm{l} \mathrm{RPMI} / 0.1 \% \mathrm{BSA}$ with/without $40 \mu \mathrm{g} / \mathrm{ml}$ exosomes. The lower part, separated by a $5 \mu \mathrm{m}$ pore size polycarbonate-membrane (Neuroprobe, Gaithersburg, MD, USA) contained $30 \mu \mathrm{l}$ RPMI/20\%FCS. Leukocytes in the lower chamber were counted after $4 \mathrm{~h}$. Where indicated, cells were pre-incubated with antibody $(10 \mu \mathrm{g} /$ $\mathrm{ml})$. Migration is presented as \% of input cells.

\section{In vivo experiments}

$\mathrm{BDX}$ rats received an i.v. injection of $\mathrm{SP}-\mathrm{Dio}_{18}$ (3)-labeled exosomes $(200 \mu \mathrm{g} / \mathrm{rat})$. After $24 \mathrm{~h}$, rats were bled, sacrificed and lymphatic organs were excised. For vaccination, rats received 3 subcutaneous injections of $2 \times 10^{6}$ ASML-lysate-loaded DC in 10d intervals. Starting with the first DC application, rats received $500 \mu \mathrm{g}$ ASMLexosomes, 2-times/week. Rats were sacrificed 3d after the $3^{\text {rd }}$ DC application. Animal experiments were Government-approved (Baden-Württemberg, Germany).

\section{Statistical analysis}

Assays were repeated at least 3 times. P-values $<0.05$ (two-tailed Student's t-test) were considered significant.

\section{Additional Files}

Additional File 1: Examples of ASML-exosome binding and uptake.
Additional File 2: Impact of ASML-exosomes on major leukocyte
subset marker expression.
Additional File 3: Tumor-exosomes and expression of signal
transduction molecules in spleen cells.
Additional File 4: Tumor-exosomes and B cell activation.
Additional File 5: Tumor-exosomes and adhesion molecule
expression in lymph node cells.
Additional File 6: Tumor-exosomes and lymphocyte activation
in vivo.
Additional File 7: Antibodies.
Additional File 8: Comparison of $100000 \mathrm{~g}$ pellet and sucrose
density gradient-enriched exosomes.

\section{Abbreviations}

AS: BSp73AS; ASML: BSp73ASML; BMC: Bone marrow cells; CTL: Cytotoxic T cells; DC: Dendritic cells; HSP: Heat shock proteins; MDSC: Myeloid-derived

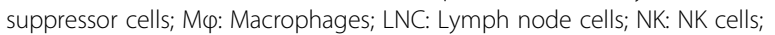
PEC: Peritoneal exudate cells; SC: Spleen cells; TC: Thymocytes; TIL: Tumor infiltrating leukocytes; Th: Helper $T$ cells; $T_{\text {reg: }}$ : Regulatory $T$ cells.

\section{Competing interests}

Authors declare no competing interest.

\section{Authors' contribution}

DZ and SR performed and evaluated experiments, MWB helped with manuscript editing, MZ planned, performed and evaluated experiments and wrote the manuscript. All authors read and approved the final manuscript.

\section{Acknowledgement}

This work was supported by the Deutsche Krebshilfe and the NCT, Heidelberg (MZ). We greatly appreciate the help of Christine Niesik with exosome preparation. Special thanks also to Prof. C. Thiery, Institut Curie, Paris, France, and Prof. D.D. Taylor, University of Louisville School of Medicine, USA, for helpful discussions on exosome purification procedures and the not yet solved problem to exclude activities of "contaminating" non-exosome vesicles.

\section{Author details}

${ }^{1}$ Department of Tumor Cell Biology, University Hospital of Surgery, Im Neuenheimer Feld 365, D-69120 Heidelberg, Germany. ${ }^{2}$ University Hospital of 
Surgery, Heidelberg, Germany. ${ }^{3}$ German Cancer Research Center, Heidelberg, Germany.

Received: 24 August 2012 Accepted: 26 November 2012 Published: 28 November 2012

\section{References}

1. Mathivanan S, Ji H, Simpson RJ: Exosomes: extracellular organelles important in intercellular communication. J Proteomics 2010, 73:1907-1920.

2. Cocucci E, Racchetti G, Meldolesi J: Shedding microvesicles: artefacts no more. Trends Cell Biol 2009, 19:43-51.

3. Pap E, Pállinger E, Pásztói M, Falus A: Highlights of a new type of intercellular communication: microvesicle-based information transfer. Inflamm Res 2009, 58:1-8.

4. Ahmed KA, Xiang J: Mechanisms of cellular communication through intercellular protein transfer. J Cell Mol Med 2011, 15:1458-1473.

5. Seow Y, Wood MJ: Biological gene delivery vehicles: beyond viral vectors. Mol Ther 2009, 17:767-777.

6. Viaud S, Théry C, Ploix S, Tursz T, Lapierre V, Lantz O, Zitvogel L, Chaput N: Dendritic cell-derived exosomes for cancer immunotherapy: what's next? Cancer Res 2010, 70:1281-1285.

7. Lamparski HG, Metha-Damani A, Yao JY, Patel S, Hsu DH, Ruegg C, LePecq JB: Production and characterization of clinical grade exosomes derived from dendritic cells. I Immunol Methods 2002, 270:211-226.

8. Tan A, De La Peña H, Seifalian AM: The application of exosomes as a nanoscale cancer vaccine. Int J Nanomedicine 2010, 5:889-900.

9. Taylor DD, Gercel-Taylor C: Exosomes/microvesicles: mediators of cancerassociated immunosuppressive microenvironments. Semin Immunopathol 2011, 33:441-454.

10. Keller S, König AK, Marmé F, Runz S, Wolterink S, Koensgen D, Mustea A, Sehouli J, Altevogt P: Systemic presence and tumor-growth promoting effect of ovarian carcinoma released exosomes. Cancer Lett 2009, 278:73-81.

11. Clayton A, Mitchell JP, Court J, Mason MD, Tabi Z: Human tumor-derived exosomes selectively impair lymphocyte responses to interleukin-2. Cancer Res 2007, 67:7458-7466.

12. Zhang HG, Kim H, Liu C, Yu S, Wang J, Grizzle WE, Kimberly RP, Barnes S: Curcumin reverses breast tumor exosomes mediated immune suppression of NK cell tumor cytotoxicity. Biochim Biophys Acta 2007, 1773:1116-1123.

13. Ashiru $\mathrm{O}$, Boutet $\mathrm{P}$, Fernández-Messina L, Agüera-González S, Skepper JN, Valés-Gómez M, Reyburn HT: Natural killer cell cytotoxicity is suppressed by exposure to the human NKG2D ligand MICA*008 that is shed by tumor cells in exosomes. Cancer Res 2010, 70:481-489.

14. Abusamra AJ, Zhong Z, Zheng X, Li M, IChim TE, Chin JL, Min WP: Tumor exosomes expressing Fas ligand mediate CD8+ T-cell apoptosis. Blood Cells Mol Dis 2005, 35:169-173.

15. Clayton A, Al-Taei S, Webber J, Mason MD, Tabi Z: Cancer exosomes express CD39 and CD73, which suppress $T$ cells through adenosine production. J Immunol 2011, 187:676-683.

16. Yang C, Kim SH, Bianco NR, Robbins PD: Tumor-derived exosomes confer antigen-specific immunosuppression in a murine delayed-type hypersensitivity model. PLoS One 2011, 6:e22517.

17. Aung T, Chapuy B, Vogel D, Wenzel D, Oppermann M, Lahmann M, Weinhage T, Menck K, Hupfeld T, Koch R, Trümper L, Wulf GG: Exosomal evasion of humoral immunotherapy in aggressive B-cell lymphoma modulated by ATP-binding cassette transporter A3. Proc Natl Acad Sci USA 2011, 108:15336-15341.

18. Khalil AA, Kabapy NF, Deraz SF, Smith C: Heat shock proteins in oncology: Diagnostic biomarkers or therapeutic targets? Biochim Biophys Acta 2011, 1816:89-104.

19. Elsner L, Muppala V, Gehrmann M, Lozano J, Malzahn D, Bickeböller H, Brunner E, Zientkowska M, Herrmann T, Walter L, Alves F, Multhoff G, et al: The heat shock protein HSP70 promotes mouse NK cell activity against tumors that express inducible NKG2D ligands. J Immunol 2007, 179:5523-5533.

20. Dai S, Wan T, Wang B, Zhou X, Xiu F, Chen T, Wu Y, Cao X: More efficient induction of HLA-A*0201-restricted and carcinoembryonic antigen (CEA)specific CTL response by immunization with exosomes prepared from heat-stressed CEA-positive tumor cells. Clin Cancer Res 2005, 11:7554-7563.

21. Hurwitz MD, Kaur P, Nagaraja GM, Bausero MA, Manola J, Asea A: Radiation therapy induces circulating serum Hsp72 in patients with prostate cancer. Radiother Oncol 2010, 95:350-358.

22. Xiu F, Cai Z, Yang Y, Wang X, Wang J, Cao X: Surface anchorage of superantigen SEA promotes induction of specific antitumor immune response by tumor-derived exosomes. J Mol Med 2007, 85:511-521.

23. Chen T, Guo J, Yang M, Zhu X, Cao X: Chemokine-containing exosomes are released from heat-stressed tumor cells via lipid raft-dependent pathway and act as efficient tumor vaccine. J Immunol 2011, 186:2219-2228.

24. Zeelenberg IS, van Maren WW, Boissonnas A, Van Hout-Kuijer MA, Den Brok MH, Wagenaars JA, van der Schaaf A, Jansen E, Amigorena S, Théry C, Figdor CG, Adema GJ: Antigen localization controls T cell-mediated tumor immunity. J Immunol 2011, 187:1281-1288.

25. Zöller M, Matzku S, Goerttler K: High incidence of spontaneous transplantable tumours in BDX rats. Br J Cancer 1978, 37:61-66.

26. Jung T, Castellana D, Klingbeil P, Cuesta Hernández I, Vitacolonna M, Orlicky DJ, Roffler SR, Brodt P, Zöller M: CD44v6 dependence of premetastatic niche preparation by exosomes. Neoplasia 2009, 11:1093-1105.

27. Nazarenko I, Rana S, Baumann A, McAlear J, Hellwig A, Trendelenburg M, Lochnit G, Preissner KT, Zöller M: Cell surface tetraspanin Tspan8 contributes to molecular pathways of exosome-induced endothelial cell activation. Cancer Res 2010, 70:1668-1678.

28. Rana S, Yue S, Stadel D, Zöller M: Towards tailored exosomes: The exosomal tetraspanin web contributes to target cell selection. Int J Biochem Cell Biol 2012, 44:1574-1584.

29. Hupalowska A, Miaczynska M: The new faces of endocytosis in signaling. Traffic 2012, 13:9-18.

30. Arch R, Wirth K, Hofmann M, Ponta H, Matzku S, Herrlich P, Zöller M: Participation in normal immune responses of a metastasis-inducing splice variant of CD44. Science 1992, 257:682-685.

31. Marhaba R, Bourouba M, Zöller M: CD44v6 promotes proliferation by persisting activation of MAP kinases. Cell Signal 2005, 17:961-973.

32. Jung $T$, Gross W, Zöller M: CD44v6 coordinates tumor matrix-triggered motility and apoptosis resistance. J Biol Chem 2011, 286:15862-15874.

33. Marhaba R, Freyschmidt-Paul P, Zöller M: In vivo CD44-CD49d complex formation in autoimmune disease has consequences on $\mathrm{T}$ cell activation and apoptosis resistance. Eur J Immunol 2006, 36:3017-3032.

34. Matzku S, Oberneder HP, Keller R, Zöller M: Natural cytotoxicity in lymphatic metastasis. I. In vitro studies using the rat tumor BSp73 and its variants. Cancer Immunol Immunother 1984, 17:100-105.

35. Mantovani A, Allavena P, Sozzani S, Vecchi A, Locati M, Sica A: Chemokines in the recruitment and shaping of the leukocyte infiltrate of tumors. Semin Cancer Biol 2004, 14:155-160.

36. Napoletano C, Rughetti A, Landi R, Pinto D, Bellati F, Rahimi H, Spinelli GP, Pauselli S, Sale P, Dolo V, De Lorenzo F, Tomao F, et al: Immunogenicity of allo-vesicle carrying ERBB2 tumor antigen for dendritic cell-based anti-tumor immunotherapy. Int J Immunopathol Pharmacol 2009, 22:647-658

37. Erkan M, Reiser-Erkan C, Michalski CW, Kleeff J: Tumor microenvironment and progression of pancreatic cancer. Exp Oncol 2010, 32:128-131.

38. Steeber DA, Venturi GM, Tedder TF: A new twist to the leukocyte adhesion cascade: intimate cooperation is key. Trends Immunol 2005, 26:9-12.

39. Caux C, Ait-Yahia S, Chemin K, de Bouteiller O, Dieu-Nosjean MC, Homey B, Massacrier C, Vanbervliet B, Zlotnik A, Vicari A: Dendritic cell biology and regulation of dendritic cell trafficking by chemokines. Springer Semin Immunopathol 2000, 22:345-369.

40. Théry C, Boussac M, Véron P, Ricciardi-Castagnoli P, Raposo G, Garin J, Amigorena S: Proteomic analysis of dendritic cell-derived exosomes: a secreted subcellular compartment distinct from apoptotic vesicles. $\mathrm{J}$ Immunol 2001, 166:7309-7318.

41. Koumangoye RB, Sakwe AM, Goodwin JS, Patel T, Ochieng J: Detachment of breast tumor cells induces rapid secretion of exosomes which subsequently mediate cellular adhesion and spreading. PLoS One 2011, 6:e24234.

42. Chalmin F, Ladoire S, Mignot G, Vincent J, Bruchard M, Remy-Martin JP, Boireau W, Rouleau A, Simon B, Lanneau D, De Thonel A, Multhoff G, et al: Membrane-associated Hsp72 from tumor-derived exosomes mediates 
STAT3-dependent immunosuppressive function of mouse and human myeloid-derived suppressor cells. J Clin Invest 2010, 120:457-471.

43. Zhang HG, Grizzle WE: Exosomes and cancer: a newly described pathway of immune suppression. Clin Cancer Res 2011, 17:959-964.

44. Szajnik M, Czystowska M, Szczepanski MJ, Mandapathil M, Whiteside TL: Tumor-derived microvesicles induce, expand and up-regulate biological activities of human regulatory T cells (Treg). PLoS One 2010, 5:e11469.

45. Wada J, Onishi H, Suzuki H, Yamasaki A, Nagai S, Morisaki T, Katano M: Surface-bound TGF-beta1 on effusion-derived exosomes participates in maintenance of number and suppressive function of regulatory T-cells in malignant effusions. Anticancer Res 2010, 30:3747-3757.

46. Ichim TE, Zhong Z, Kaushal S, Zheng X, Ren X, Hao X, Joyce JA, Hanley HH, Riordan NH, Koropatnick J, Bogin V, Minev BR, Min WP, Tullis RH: Exosomes as a tumor immune escape mechanism: possible therapeutic implications. J Trans/ Med 2008, 6:37.

47. Peng $P$, Yan $Y$, Keng S: Exosomes in the ascites of ovarian cancer patients: origin and effects on anti-tumor immunity. Oncol Rep 2011, 25:749-762.

48. Föger N, Marhaba R, Zöller M: CD44 supports T cell proliferation and apoptosis by apposition of protein kinases. Eur J Immunol 2000, 30:288828-99.

49. Kyosseva SV, Harris EN, Weigel PH: The hyaluronan receptor for endocytosis mediates hyaluronan-dependent signal transduction via extracellular signal-regulated kinases. J Biol Chem 2008, 283:15047-15055.

50. Kurosaki T, Maeda A, Ishiai M, Hashimoto A, Inabe K, Takata M: Regulation of the phospholipase C-gamma2 pathway in B cells. Immunol Rev 2000, 176:19-29.

51. Zöller M, Matzku S: Solid tumor-derived target cell susceptibility to macrophages and natural killer/natural cytotoxic cells in the rat. Immunobiology 1983, 164:349-360.

52. Rose $\mathrm{DM}$, Alon $\mathrm{R}$, Ginsberg $\mathrm{MH}$ : Integrin modulation and signaling in leukocyte adhesion and migration. Immunol Rev 2007, 218:126-34.

53. Kveberg L, Jiménez-Royo P, Naper C, Rolstad B, Butcher GW, Vaage JT, Inngjerdingen M: Two complementary rat NK cell subsets, Ly49s3+ and NKR-P1B+, differ in phenotypic characteristics and responsiveness to cytokines. J Leukoc Biol 2010, 88:87-93.

54. Matzinger P: The JAM test. A simple assay for DNA fragmentation and cell death. J Immunol Methods 1991, 145:185-192.

doi:10.1186/1478-811X-10-37

Cite this article as: Zech et al:: Tumor-exosomes and leukocyte activation: an ambivalent crosstalk. Cell Communication and Signaling 2012 10:37.

\section{Submit your next manuscript to BioMed Central and take full advantage of:}

- Convenient online submission

- Thorough peer review

- No space constraints or color figure charges

- Immediate publication on acceptance

- Inclusion in PubMed, CAS, Scopus and Google Scholar

- Research which is freely available for redistribution 